\title{
Synergism between abdominal and pelvic floor muscles in healthy women: a systematic review of observational studies
}

\author{
Sinergismo da musculatura abdomino-pélvica em \\ mulheres hígidas: uma revisão sistemática
}

\author{
Lia Ferla, Caroline Darski, Luciana Laureano Paiva, Graciele Sbruzzi, Adriane Vieira*
}

Universidade Federal do Rio Grande do Sul (UFRGS), Porto Alegre, RS, Brazil

\begin{abstract}
Introduction: The training of the pelvic floor muscles is widely used for treating pelvic floor dysfunctions, like urinary incontinence. During the training, abdominal contractions are avoided; however several studies support the use of the synergy between these muscle groups. Objective: Carrying out a systematic review of studies that seek to identify the presence of synergy between the muscles of the abdomen and the pelvic floor and its functionality in women without pelvic floor dysfunction. Methodology: To conduct the review, we have followed the recommendations proposed by the Cochrane Collaboration for systematic reviews. The literature search included the databases SCIELO, PEDro, MEDLINE, Cochrane CENTRAL and EMBASE, and manual research, the starting date of the databases until August 2013. We included cross observational studies with healthy women who were assessed to find the presence of synergy between the abdominal muscles and the pelvic floor. Results: We included 10 articles and they all showed the existence of synergy between the abdominal and pelvic floor muscles in healthy women in the supine, sitting and standing positions. Conclusion: Thus, we can conclude that there is synergy between the muscles of the abdomen and the pelvic floor in healthy women. Better understanding the behavior of these muscles and synergy may favor the development of strategies for the prevention and treatment of disorders of the female pelvic floor muscles.
\end{abstract}

Keywords: Pelvic Floor. Abdominal Muscle. Women. Review.

\footnotetext{
*LF: Doctoral Student, e-mail: lyaferla@hotmail.com

CD: MSc Student, e-mail: carolzinha_darski@hotmail.com

LLP: PhD, e-mail: lucianalaureanopaiva@gmail.com

GS: PhD, e-mail: graciele.sbruzzi@ufrgs.br

AV: PhD, e-mail: adriane.vieira@gmail.com
} 


\section{Resumo}

Introdução: $O$ treinamento dos músculos do assoalho pélvico é amplamente utilizado no tratamento de disfunções do assoalho pélvico, como a incontinência urinária, e durante sua execução evita-se a contração abdominal, entretanto vários estudos defendem a utilização do sinergismo entre estes grupos musculares. objetivo: Revisar sistematicamente os estudos que buscam identificar a presença de sinergismo entre os músculos do abdômen e do assoalho pélvico e sua funcionalidade em mulheres sem disfunções do assoalho pélvico. Metodologia: Para a realização da revisão, foram seguidas as recomendações propostas pela Colaboração Cochrane para revisões sistemáticas. A busca na literatura incluiu as bases SCIELO, PEDro, MEDLINE, Cochrane CENTRAL e EMBASE, além de busca manual, do início das bases até agosto de 2013. Foram incluídos estudos observacionais transversais com mulheres saudáveis que foram avaliadas quanto à presença de sinergismo entre os músculos abdominais e do assoalho pélvico. Resultados: Foram incluídos 10 artigos e todos demonstraram a existência de sinergismo entre os músculos abdominais e músculos do assoalho pélvico em mulheres saudáveis nas posturas supina, sentada e em ortostase. Conclusão: Dessa forma, pode-se concluir que há sinergismo entre os músculos do abdômen e do assoalho pélvico em mulheres saudáveis. Conhecer melhor o comportamento dessas musculaturas e do sinergismo pode favorecer a elaboração de estratégias de prevenção e tratamento das disfunções dos músculos do assoalho pélvico feminino.

Palavras-chave: Assoalho Pélvico. Músculos Abdominais. Transverso do Abdômen. Mulheres. Revisão.

\section{Introduction}

The pelvic floor (PF) is composed of the muscle, ligament and fascia structures which span the area underneath the pelvis. In women, the role of PF is to support the pelvic viscera, controlling urinary and fecal continence and allowing the passage of the fetus during labor (1). The phasic contraction of the pelvic floor muscles (PFM) produces a movement of the entire structure of the PF in the ventral and cranial direction, along with an anterior movement $(2,3)$. During the abrupt increase in intra-abdominal pressure (IAP), the PFM should activate fast fibers to counteract the increase in pressure and prevent the downward movement of the bowels and urinary discharge (4).

Alterations in the structure and function of the PF can cause dysfunctions. These dysfunctions are common, affecting one in nine women, with its prevalence increasing as age increases. Among these dysfunctions, urinary incontinence (UI) is the most commonly related $(5,6,7,2)$. Pelvic floor muscle training (PFMT), created by Arnold Kegel in the 1940s, is used to strengthen the PFM in women with dysfunctions, especially UI $(8,9)$. Training these muscles is recommended as the first option of treatment for UI (9). During the training, patients are instructed to avoid contracting the abdominal muscles, especially the transversus abdominis (TrA), since it is considered that the increase in intra-abdominal pressure (IAP) caused by the contraction of these muscles has a negative impact on the PFM (10).

However, several studies suggest that the $\operatorname{Tr} A$ muscle helps with lumbar support, and it is the first muscle to be activated when the stability of the lumbar is challenged by rapid movements of the upper limbs; avoiding the contraction of this muscle during the PFM training might counteract the synergistic action of these muscle groups $(11,12)$. The existence of synergism between the PFM and the TrA has been the basis for recent studies that support the idea that the PFM are an intrinsic part of the physiological complex of the abdominal muscles (13). These studies suggest that training the PFM and the deep abdominal muscles should be carried out concomitantly so as to treat PF dysfunctions (10). Despite the fact that synergism has been the subject of study of many researchers for some time, a consensus has not been reached regarding the synergy between abdominal muscles and PFM, since this synergy can be altered in women with PF dysfunctions (14).

Only one systematic review that talked about synergism between the abdominal and pelvic floor muscles in healthy women was found in the literature (15). The goal of this study was to identify if there were evidences to support the hypothesis that there is a co-contraction of the TrA when the PFM are contracted and vice-versa. The authors (15) came to the conclusion that there was some evidence that a co-contraction 
of the TrA occurs when the PFM are contracted, but a co-contraction of the PFM may be lost or weakened in patients with symptoms of PF dysfunctions. However, this systematic review has many methodological flaws, and it was even refuted, in a letter to the editor, by authors mentioned in the study (16).

Thus, it is relevant to investigate if there is scientific evidence for the presence of synergism between the abdominal muscles and the PF in healthy women by verifying if the contraction of one of these muscle groups is accompanied by the contraction of the other. The goal of this study is to perform a systematic review of studies that aim to identify the presence of synergism between abdominal muscles and the PF, and how it functions in healthy women.

\section{Methodology}

This study followed the recommendations of the Cochrane Collaboration (17).

\section{Eligibility criteria}

The studies included in this systematic review were cross-sectional observational studies with healthy women. These studies evaluated the participants as to the presence of synergism between the abdominal muscles and the PF, that is, they assessed if the contraction of one of these muscle groups was accompanied by the contraction of the other during the assessment of the abdominal groups, the PF or both.

\section{Research strategy}

To reach the goal of this study, a literature research was carried out in electronic databases: SCIELO, PEDro, MEDLINE (accessed via PubMed), Register of Controlled Trials (Cochrane CENTRAL) and EMBASE, from starting date of the databases until August 2013. In addition, a manual research of the references of published studies on the subject was performed. The full research strategy used on PubMed can be found in Table 1. There was no language restriction in the research.

\section{Selection of the studies and data extraction}

In the first stage of the selection, two authors, independently and in duplicate form, reviewed the title and abstract of the articles found by the research engines. All abstracts that did not provide sufficient information concerning the inclusion and exclusion criteria were selected, so the full article could be read. In the second stage, the same reviewers independently assessed the full articles and made their selection according to the eligibility criteria.

The same reviewers conducted, independently and in duplicate, data extraction with regard to the methodological characteristics of the studies, interventions and outcomes using standardized forms; disagreements were resolved by consensus or by a third reviewer. Authors were contacted in order to ask questions and request full articles.

Table 1 - Research strategy used on PubMed

\begin{tabular}{ll}
\hline \#\#1 & "Abdominal Muscles"[Mesh] OR "Abdominal Muscles" OR "Abdominal Muscle" OR "Muscle, Abdominal" OR "Muscles, \\
& Abdominal" OR "Abdomen"[Mesh] OR "Abdomen" OR "abdomens" OR "transversus abdominis" \\
& "Pelvic Floor"[Mesh] OR "pelvic floor" OR "Floor, Pelvic" OR "Pelvic Diaphragm" OR "Diaphragm, Pelvic" OR "Diaphragms, \\
\#\#2 & Pelvic" OR "Pelvic Diaphragms" OR "Pelvic Floor Muscles" OR "abdomino-pelvic musculature" OR "perineal musculature" \\
OR "Perineum"[Mesh] OR "perineum" OR "perineums" OR "Pelvis"[Mesh] OR "pelvis" OR "Pelvic Region" OR "Region, Pelvic" \\
OR "perineal function" OR "pelvic floor contraction" \\
"Women"[Mesh] OR women OR woman OR "Women's Groups" OR "Group, Women's" OR "Groups, Women's" OR "Women \\
Groups" OR "Women's Group" OR "Pelvic Floor"[Mesh] OR "pelvic floor" OR "Floor, Pelvic" OR "Pelvic Diaphragm" OR \\
"Diaphragm, Pelvic" OR "Diaphragms, Pelvic" OR "Pelvic Diaphragms" OR "Pelvic Floor Disorders"[Mesh] OR "pelvic floor \\
disorders" OR "Disorder, Pelvic Floor" OR "Disorders, Pelvic Floor" OR "Pelvic Floor Disorder" OR "Pelvic Floor Diseases" \\
OR "Disease, Pelvic Floor" OR "Diseases, Pelvic Floor" OR "Pelvic Floor Disease" OR "Urinary Incontinence"[Mesh] OR \\
"Urinary Incontinence" OR "Incontinence, Urinary" OR "Urinary Incontinence, Urge"[Mesh] OR "Urinary Incontinence, Urge" \\
OR "Urinary Reflex Incontinence" OR "Incontinence, Urinary Reflex" OR "Urinary Urge Incontinence" OR "Urge Incontinence" \\
OR "Incontinence, Urge" OR "Urinary Incontinence, Stress"[Mesh] OR "Urinary Incontinence, Stress" OR "Urinary Stress \\
Incontinence" OR "Incontinence, Urinary Stress" OR "Stress Incontinence, Urinary" \\
\#1 AND \#2 AND \#3 \\
\#4
\end{tabular}


Description of the methodology quality

The Strengthening the Reporting of Observational Studies in Epidemiology (STROBE) initiative proposes items for describing observational studies, which, even though they do not have the objective of evaluating the quality of observational studies, allow authors to better describe them $(18,19)$. Six criteria were considered when describing the methodological quality of the studies included in this review: (1) detailing of the theoretical framework and reasons for performing the research; (2) presentation of the eligibility criteria; (3) presentation of the sources and methods of selection of participants; (4) definition of the sample size; (5) description of the characteristics of the study participants (e.g., demographic, clinical and social data); (6) presenting the main findings relating to the goals of the study.

\section{Results}

Description of the studies

The result strategy resulted in 5212 studies. Of these studies, 120 remained for the detailed analysis of the article. In the end, 10 studies met all the inclusion criteria and were included. Figure 1 shows the flowchart of the studies included and Table 2 shows the characteristics of these articles. The average number of participants in the trials was 10 , and the smaller-scale study had four participants (23), and the one with the greatest number had 20 participants (24).

Seven studies (21 - 23, 25 - 28) evaluated the abdominal muscles and, among these, all used electromyography (EMG), four used surface EMG (22 - 25 to 27), one used needle EMG (21) and two used surface and needle EMG $(23,28)$. Several instruments were used to evaluate the PFM: needle EMG (20), intravaginal probe EMG (despite being intravaginal, this considered to be a surface EMG) (21 - 28), intravaginal probe and pressure EMG $(22,23,26)$, transabdominal ultrasound (24) and modified intravaginal probe (pressure and EMG) $(25,27)$. The intravaginal probe EMG was the predominant evaluation method to record the activation of the PFM, used in seven (21-23, 25 - 28) of the ten studies. The evaluation of the abdominal muscles and PFM was carried out, most often, in the supine position in all ten studies (20 - 29) and some also conducted assessments in sitting (27) and standing $(22,23,27)$ positions.

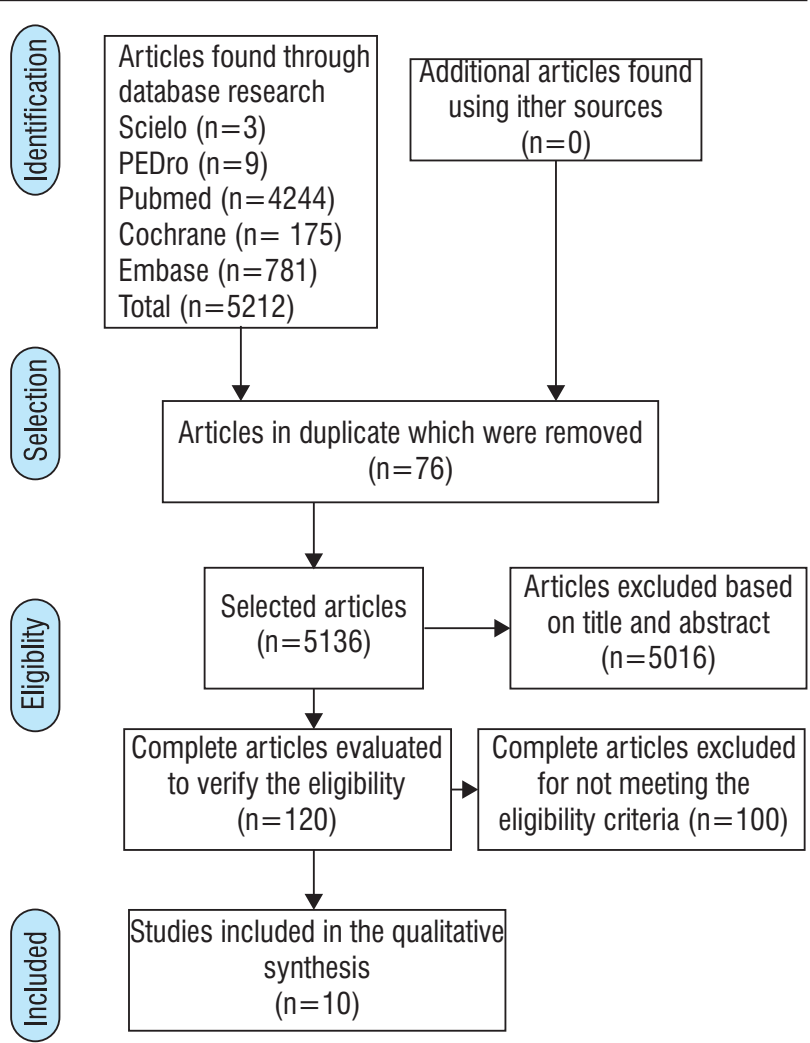

Figure 1 - Flowchart of the studies included in this review

\section{Description of methodological quality}

Regarding the criteria mentioned in the description of the methodological quality of the studies included in this review, all articles (21 - 29) met the criteria in their introduction and methodology, respectively, detailing the theoretical framework and the reasons for performing the research. As to the presentation of the sources and methods for selecting the participants and defining the sample size, none of the studies (21 - 29) included such items in their methodology. But the description of characteristics of the participants (e.g., demographic, clinical and social data) was present in $50 \%$ of the studies $(21,22$, $24,28,29)$. As regards the criterion of presentation of the main findings relating to the objectives of the study, only one study (23) did not meet this criterion.

\section{Synergy}

As to the presence of synergism between the PFM and the abdominal muscles, all the selected studies found a pattern of synergy between these muscles in healthy women. 


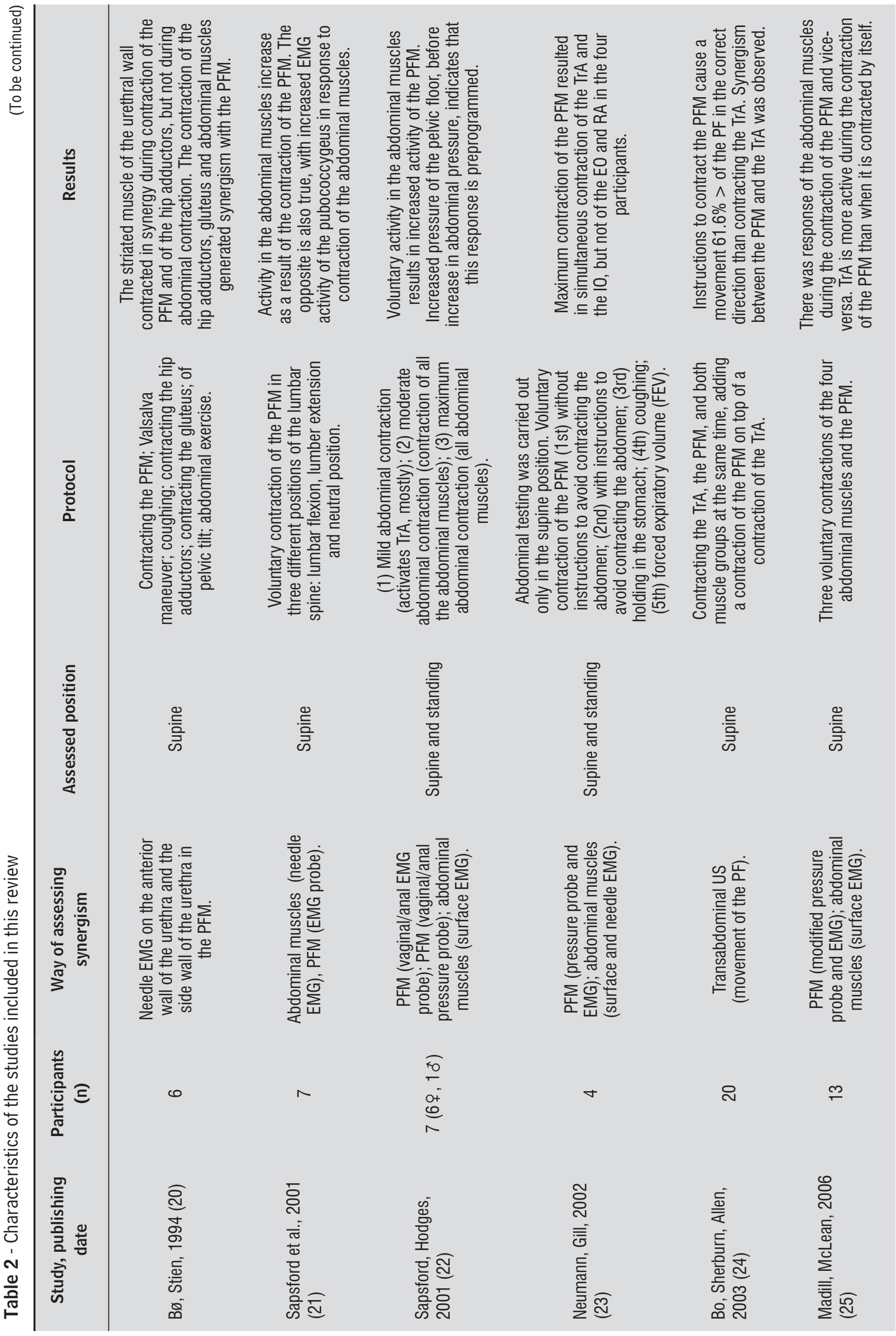




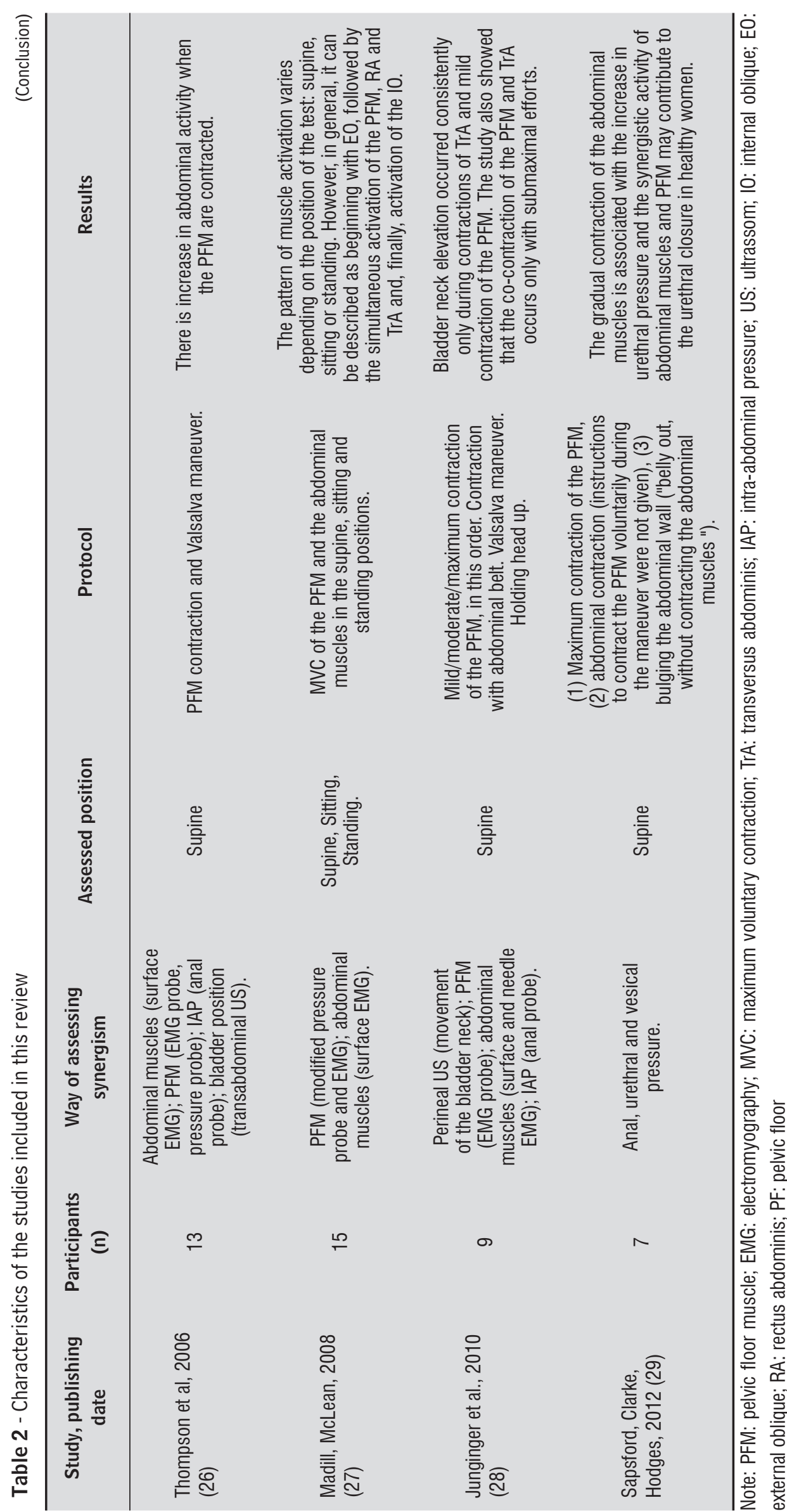


Table 3 - Description of the methodological quality of the studies

\begin{tabular}{lllllll}
\hline \multicolumn{1}{c}{ Study } & (1) & (2) & (3) & (4) & (5) & (6) \\
\hline Bø, Stien, 1994 (20) & Yes & Yes & No & No & No & Yes \\
Sapsford et al., 2001 (21) & Yes & Yes & No & No & Yes & Yes \\
Sapsford, Hodges, 2001 (22) & Yes & Yes & No & No & Yes & Yes \\
Neumann, Gill, 2002 (23) & Yes & Yes & No & No & No & No \\
Bo, Sherburn, Allen, 2003 (24) & Yes & Yes & No & No & Yes & Yes \\
Madill, McLean, 2006 (25) & Yes & Yes & No & No & No & Yes \\
Thompson et al., 2006 (26) & Yes & Yes & No & No & No & Yes \\
Madill, McLean, 2008 (27) & Yes & Yes & No & No & No & Yes \\
Junginger et al., 2010 (28) & Yes & Yes & No & No & Yes & Yes \\
Sapsford, Clarke, Hodges, 2012 (29) & Yes & Yes & No & No & Yes & Yes \\
\hline
\end{tabular}

The first study found was published in 1994 by Bø and Stien (20). In this study it was observed that the PFM contract synergistically during the contraction of the abdominal muscles. Thus, the authors suggest that abdominal exercises can strengthen the PFM.

The second study found was published in 2001 by Sapsford et al. (21). It investigated the response of the abdominal muscles during voluntary contraction of the PFM in three positions of the lumbar spine. These authors observed that the amplitude of the EMG of the TrA was higher than the other abdominal muscles in all positions of the spine, and the amplitude of the EMG of the TrA was higher when observed with the lumbar spine in a neutral position. It was also verified that the TrA acted in synergy with the PFM, that is, an increase of the muscular activity in the PF was accompanied by an increase in activity of the TrA. In the same study, an additional experiment was performed. It was similar to the main experiment, with two participants using the needle EMG in both the abdominal muscles and the PFM. In the case of the PFM, the needle was placed on the right side of the pubococcygeus through the side vaginal wall. The objective was to verify the pattern of activity of the pubococcygeus during voluntary contraction of the abdominals. It was observed that during the contraction of the abdominal muscles there was increased activity of the pubococcygeus muscle in the participants.

Also in 2001, Sapsford and Hodges (22) aimed to determine whether the voluntary contraction of the abdominal muscle is associated with muscle activity in the PF in the supine and standing positions, and if so, whether this response depends on the magnitude of the abdominal contraction. The authors found that during abdominal contraction there is increased activity in the PFM, in all levels of contraction (mild, moderate, maximum), although this increase was higher at maximum contraction. The results obtained when participants were standing were similar to data found in the supine position, in which the contraction of the abdominal muscles was associated with an increased electromyographic activity of the PFM. This finding indicates that the mechanical response of the PFM precedes the abdominal muscles and the PFM activity is not simply a response or increase in IAP. The increased pressure in the pelvic floor before the increased IAP indicates that this response is preprogrammed and the authors believe that training the abdominal muscles can be useful in the treatment of dysfunctions of the PFM. Although the study by Sapsford and Hodges (2001) (22) had the participation of a man, the results and discussion were different for men and women 
and, in this study, we considered the data regarding the six women.

The authors Neumann and Gill (23) developed, in 2002, a study with four participants. One of its aims was to investigate the interaction between the abdominal muscles and the PF in the supine (neutral lumbar spine) and standing positions. The participants underwent an abdominal test (lift your head and shoulders simultaneously off the bed and hold the position for three seconds) only in the supine position in order to obtain a maximum activation of all abdominal muscles. This test was used to normalize the data from the abdominal muscles throughout the study. The collection protocol consisted of five activities performed in the supine position, with four of those tested also in the standing position. The MVC of the PFM without guidance to avoid contracting the abdomen caused the activation of TrA up to $66 \%$ of its maximum EMG activity. The MVC of the PFM with guidance to avoid contracting the abdomen (supine posture) only activated up to $26 \%$ of its maximum contraction, that is, the activity of the PFM was reduced in an attempt to isolate the contraction. In addition, during the contraction of the PFM there was no activity of the abdominal muscles, regardless of the lumbar spine position. Contracting only the TrA produced a $12 \%$ increase in its EMG activity and the PFM were activated to $40 \%$ of its capacity, which is higher than its activity of $26 \%$ during MVC of the PFM without contraction of the abdomen. With this, the authors showed that there is presence of synergy between the abdominal muscles and the PF.

A study by Bo, Sherbun and Allen (24) in 2003 assessed the presence of synergy between the abdominal muscles and the PF using a transabdominal US, comparing three different instructions for contraction of the abdominal muscles and PFM. Comparisons were made by evaluating the movement of the PF. The average of six contractions for each instruction was completed. Even though the capacity for PFM contraction had been previously observed during data collection, one participant showed caudal movement of the PF when instructed to contract the PFM. In the instruction to contract the TrA, six participants (30\%) showed caudal movement of the PF. During instruction for simultaneous contraction of the TrA and PFM, two participants showed caudal movement of the PF. This study suggests that the isolated contraction of the PFM is more efficient for PF elevation than contracting the $\operatorname{Tr} A$ alone, and also more efficient than the associated contraction of TrA and PFM.

Authors Madill and McLean (25) published, in 2006, a study that aimed to describe the relationship between the activation of the PFM, the activation of abdominal muscles while performing MVC of each of the four abdominal muscles and the PFM. The study showed that the TrA was more active during the contractions of the PFM than during its isolated contraction. In 2008 (27), the same authors (25) conducted a study to observe, through MVC of the abdominal muscles and the PFM in the supine, sitting and standing positions, the synergistic patterns of these muscles. They found that all the abdominal muscles were activated when the PFM were contracted.

In 2006, Thompson et al. (26) published a study that had the goal of investigating the activation pattern of the abdominal and PFM during the contraction of the PFM. The participants were put in the supine position, with the lumbar spine in a neutral position. In this study, the authors observed only three of the abdominal muscles: IO, EO and RA. They considered that an electrode on the IO could also access the activity of the TrA, which is located directly under it. Comparing the muscles while resting and while contracting the PFM, the authors concluded that during the contraction of the PFM there is an increase in the activity of the IO and EO.

Junginger et al. (2010) (27) observed the movement of the bladder neck using a perineal US, and also using the EMG of the abdominal muscles and the PFM. This was carried out during six activities: (1) mild contraction of the PFM; (2) moderate contraction of the PFM; (3) isolated contraction of the TrA; (4) contraction of the abdominal muscles; (5) Valsava maneuver; (6) flexing of the upper body. The authors observed that the bladder neck was elevated consistently only during contraction of the PFM and isolated contraction of the TrA. When other abdominal muscles were contracted there was increase in intra-abdominal pressure and the activity of the PFM was not enough to elevate the bladder.

The last study found, by Sapsford, Clarke and Hodges (2012) (29), tested the hypothesis that the activation of deep abdominal muscles is associated to an increase in urethral pressure comparable to the increase obtained during the voluntary contraction of the PFM. These authors observed that the gradual contraction of the abdominal muscles is associated with an increase in urethral pressure, and the 
synergetic activity between the abdominal muscles and the PFM may contribute to the urethral closure in healthy women.

\section{Discussion}

The goal of this study was to perform a systematic review to identify if there is scientific evidence of the presence of synergy between the abdominal muscles and the PFM in healthy women. To this date, only one systematic review (14) about this subject has been published, and it has several methodological flaws. In it, the authors concluded that there is some evidence that a co-contraction of the TrA occurs when the PFM are contracted. In our systematic review, we observed that all studies brought evidence of the presence of synergy between the abdominal muscles and the PFM, that is, there is a response of the abdominal muscles during the contraction of the PFM and viceversa. It is important to note that none of the studies met all the criteria regarding methodological quality considered in this review. Five studies met four of the six criteria chosen to describe the methodological quality $(21,22,24,28,29)$. None of the studies presented the sources and methods for selecting the participants or defining the size of the sample. This puts into question the reliability of the studies present in this review. The fact that they used different evaluation instruments also limited the comparison between studies.

The most common instrument used to assess the PFM and the abdominal muscles was the EMG, especially the surface EMG. This technique registers bioelectric extracellular activity generated by muscle fibers. It can be carried out using surface electrodes, which captures the activity of several motor units, or using a needle, which captures the activity of fewer motor units (30). Despite the fact that data collection using EMG still requires standardization of a few variables - for example, the position of the sensor and the patient, the number of contractions for evaluating phasic fibers and the amount of time the contraction must be held for evaluating tonic fibers - this is a tool used very often in research and in clinical practice, because it has good reproducibility and reliability (31). The type of electrode and the parameters of analysis are important factors in the discussion about surface electromyography. According to Deffieux et al. (32), surface electrodes are more suited for capturing the electronic activity of the PFM because they engage and capture the signal better than the needle electrodes, which are painful and can move during the movement caused by the muscular contraction. Thus, the fact that an intravaginal EMG probe was used in four of the selected studies $(21,23,26,28)$ is due to the fact that it is an instrument described in the literature as a reliable method for evaluating muscular activity of the PF in healthy women.

The supine position (20 - 29) is considered to be the most convenient for evaluating the PFM, for both the therapist and the patient, and that is possibly the reason why it was used in the ten studies (20 - 29) that make up this review. However, this position is only one of the behaviors that the PF may have, since urinary incontinence in women with SUI depends on physical effort and often increases when they are standing, since in this position there is the action of gravity acting on the PF $(34,35)$.

Only three studies $(22,23,27)$ evaluated other positions in addition to the supine. The study of Madill and McLean (27) did not identify differences in the activation of the PFM between the supine and standing positions, suggesting that gravity had little or no impact on the activation of the PFM. The comparison study by Madill and McLean (27), with results found in a study with women who suffer from SUI, such as the one by Rett et al. (35), suggests that there is difference in the behavior of the PF of healthy women and the PF of women with dysfunctions. The authors identified, using an intravaginal EMG probe, that the amplitude of the contractions of the PFM was higher in the supine position and subsequently lower in the sitting and standing positions.

The analyzed studies (20 - 29) can be divided into three groups: (1) response of the TrA muscle during contraction of the PFM $(21,26)$; (2) PFM response during abdominal contraction (20 - 22); (3) TrA response during contraction of the PFM and response to contraction of the $\operatorname{TrA}(23,25,27-29)$. All groups provided evidence of the presence of synergism between the abdominal muscles and the PFM in the supine position, that is, there is response of the abdominal muscles during the contraction of the PFM and vice versa.

Among the studies of group 3 we can identify two approaches. Bo, Sherbun and Allen (24), despite identifying the presence of synergism between the abdominal muscles and the PF, maintain that the isolated contraction of the PFM is more effective 
than the isolated contraction of the TrA muscle, and also more efficient than the associated contraction of the TrA and the PFM. They claim that the contraction of the TrA, by increasing the IAP, hinders the elevation of the PF. They also say that the TrA has nothing to do with the urethra and it does not support its function, which is only associated with the activation of the PFM. In women with weak PFM, training the PFM by activating the TrA without instructions for voluntary and simultaneous contractions of the PFM could, with the increased IAP and without an effective action on urethra closure, make the UI worse (24).

Neumann e Gill (2002) (23), on the other hand, argue that the MVC of the PFM, with instruction to avoid contracting the abdominal muscles, reduces its EMG activity, and that the contraction of the TrA is capable of increasing the EMG activity of the PFM more than the MVC. According to Sapsford et al. (21) and Neumann and Gill (23), the practice of avoiding the contraction of the abdominal muscles during the PFM training with women suffering from UI should be reconsidered, since the activity in the abdominal muscles is a natural response to the contraction of the PFM and vice-versa. This fact may be confirmed by the study by Korelo et al. (36) that verified if strengthening the abdomen influences the PFM in young, healthy women. In the study, the women were divided into two groups: one received instructions to contract the PFM while contracting the abdominal muscles at the same time; the other group was not instructed to contract the PFM. The authors suggested that associating exercises that strengthen abdominal muscles with the PFM may increase the strength and function of these muscle groups, and not associating them might harm the function of the PF. Recently, Arab e Chehrehrazi (2011) (37) demonstrated in their study, which compared healthy and incontinent women, that a co-activation of the abdominal muscles occurs during the contraction of the PFM equally in both groups.

Our review analyzed 10 studies, five more than the review by Bo et al. about the same subject (15), probably because it counted with four more years and used a more sensible and complete research strategy. The review by Bo et al. (15) did not follow the recommendations proposed by the Cochrane Collaboration (17) for systematic reviews, such as well-defined eligibility criteria, specific ways of selecting the studies, extracting data and describing the methodological quality of the studies included in the review. Besides, despite the fact that the authors (15) concluded that a co-contraction of the PFM during the contraction of the TrA might be lost or weakened in patients with PF dysfunctions, they did not include studies that assessed women who suffered from UI.

The limitations of our study are the restriction of researching articles only in English and Portuguese and the difficulty comparing the studies because of the use of different forms of evaluation of the synergy between the abdominal muscles and the PFM.

Research on the synergy between the abdominal muscles and the PF provide the physical therapist who works in the treatment of dysfunctions involving both pelvic and abdominal areas with a greater insight into the normal functioning of these body regions. With this review, we can demonstrate that studies suggest the existence of a synergism between the abdominal muscles and the PF in healthy women, and the associated contraction of the TrA and the PFM can be possibly useful to optimize the functionality of the PFM. However, it is still not possible to state how this synergy could be used to improve the functionality of the PFM. There is also the need for systematic reviews to assess women with disorders of the PFM, studies comparing women with and without dysfunction of the PFM, as well as studies about the use of abdominal training in the treatment of disorders of the PFM, in order to better understand this function and choose more effective treatments for dysfunctions of the PF.

\section{Final considerations}

All the studies selected for this review showed the existence of a synergy between the abdominal muscles and the PF in healthy women in the supine, sitting and standing positions. However, none of the studies included in this review presented the sources and methods for selecting the participants and defining the sample size, which limits the reliability of the findings. Better understanding the behavior of the abdominal muscles and the PF, and the synergism between these muscle groups may favor the development of strategies for the prevention and treatment of disorders of the female PFM. 


\section{References}

1. Grosse D, Sengle, J. Reeducação Perineal. $1^{\text {st }}$ ed. Barueri: Manole; 2002.

2. Baessler K, et al. Pelvic floor re-education: principles and practice. $2^{\text {nd }}$ ed. London: Springer; 2008.

3. Messelink B, Benson T, Berghmans B, Bo K, Corcos J, Fowler C, et al. Standardization of Terminology of Pelvic Floor Muscle Function and Dysfunction: Report From the Pelvic Floor Clinical Assessment Group of the International Continence Society. Neurourol Urodyn. 2005 ; 24:374-80.

4. Corton MM. Anatomy of the Pelvis: How the Pelvis Is Built for Support Clinical. Obstet Gynecol. 2005; 48(3): $611-26$.

5. Baracho E. Fisioterapia aplicada à Saúde da Mulher. $5^{\text {nd }}$ ed. Rio de Janeiro: Guanabara Koogan; 2012.

6. Bump RC, Norton PA. Epidemiology and natural history of pelvic floor dysfunction. Obstet Gynecol Clin North Am. 1998; 25(4).

7. Sung VW, Hampton BS. Epidemiology of Pelvic Floor Dysfunction. Obstet Gynecol Clin North Am. 2009; 36: 421-43.

8. Kegel AH. Progressive resistence exercise in the functional restoration of the perineal muscles. Am J Obstet Gynecol. 1948; 4:238-48.

9. Thüroff JW, Abrams P, Andersson KE, Artibani W, Chapple CR, Drake MJ, et al. EAU Guidelines on Urinary Incontinence. Eur Urol. 2011; 59:387-400.

10. Sapsford R. Rehabilitation of pelvic floor muscles utilizing trunk stabilization. Man Ther. 2004; 9:3-12.

11. Hodges PW, Richardson CA. Feedforward contraction of transversus abdominis is not influenced by the direction of arm movement. Exp Brain Res. 1997; 114:362-70.

12. Hodge PW, Hides J, Richardson C. Fisioterapia Para Estabilização Lombopélvica. $2^{\text {nd }}$ ed. São Paulo: Phorte; 2012.

13. Berglas H, Rubin IC. Study of the supportive structures of the uterus by levator myography. Surg Gynecol Obstet. 1953; 97:677-92.
14. Bo K, Ingeborg HB, Majida M, Engh ME. Constriction of the levator hiatus during instruction of pelvic floor or transversus abdominis contraction: a 4D ultrasound study. Int Urogynecol J. 2009; 20:27-32.

15. Bo K, Morkved S, Frawley H, Sherburn M. Evidence for Benefit of Transversus Abdominis Training Alone or in Combination With Pelvic Floor Muscle Training to Treat Female Urinary Incontinence: A Systematic Review. Neurourol Urodyn. 2009; 28:368-73.

16. Sapsford RR, Hodges PW, Smith M. Systematic Review: Abdominal or Pelvic Floor Muscle Training. Neurourol Urodyn. 2010; 29:800-1.

17. Higgins J, Green S. Cochrane handbook for systematic reviews of interventions 5.0. Chichester: John Wiley \& Sons; 2011.

18. Malta M, Cardoso LO, Bastos FI, Magnanini MMF, Silva CMFP. Iniciativa STROBE: subsídios para a comunicação de estudos observacionais. Rev Saude Publica. 2010;44(3):559-65.

19. Von Elm E, Altman DG, Egger M, Pocock SJ, Gøtzsche PC, Vandenbroucke JP, et al. Strengthening the Reporting of Observational Studies in Epidemiology (STROBE) statement: guidelines for reporting observational studies. BMJ. 2007; 335(7624):806-8.

20. $B \varnothing K$, Stien R. Needle EMG registration of striated urethral wall and pelvic floor muscle activity patterns during cough, valsalva, abdominal, hip adductor, and gluteal muscles contractions in nulliparous healthy females. Neurourol Urodyn. 1994;13:35-41.

21. Sapsford RR, Hodges PW, Richardson CA, Cooper DH, Markwell SJ, Jull GA. Co-activation of the abdominal and pelvic floor muscles during voluntary exercises. Neurourol Urodyn. 2001; 20:31-42.

22. Sapsford RR, Hodges PW. Contraction of the Pelvic Floor Muscles During Abdominal Maneuvers. Arch Phys Med Rehabil. 2001; 82(8):1081-8.

23. Neumann P, Gill V. Pelvic floor and abdominal muscle interaction: EMG activity and intra-abdominal pressure. Int Urogynecol J. 2002; 13:125-32.

24. Bo K, Sherburn M, Allen T. Transabdominal ultrasound measurement of pelvic floor muscle activity when activated directly or via a transversus abdominis muscle contraction. Neurourol Urodyn. 2003; 22:582-8. 
25. Madill SJ, McLean L. Relationship between abdominal and pelvic floor muscle activation and intravaginal pressure during pelvic floor muscle contractions in healthy continent women. Neurourol Urodyn. 2006; 25:722-30.

26. Thompson JA, O’Sullivan PB, Briffa NK, Neumann P. Differences in muscle activation patterns during pelvic floor muscle contraction and valsalva manouevre. Neurourol Urodyn. 2006; 25:148-55.

27. Madill SJ, McLean L. Quantification of abdominal and pelvic floor muscle synergies in response to voluntary pelvic floor muscle contractions. J Electromyogr Kinesiol. 2008; 8(6):955-64.

28. Junginger B, Baessler K, Sapsford RR, Hodges PW. Effect of abdominal and pelvic floor tasks on muscle activity, abdominal pressure and bladder neck. Int Urogynecol J. 2010; 21:69-77.

29. Sapsford RR, Hodges PW. The effect of abdominal and pelvic floor muscle activation on urine flow in women. Int Urogynecol J. 2012; 23:1225-30.

30. Vodusek DB. Electromyography In: Evidence based physical therapy for the pelvic floor. Amsterdam: Elsevier; 2007: 53-63.

31. Vodusek DB. The role of electrophysiology in the evaluation of incontinence and prolapsed. Obstet Gynecol. 2002; 14:509-14.

32. Deffieux X, Hubeaux K, Porcher R, Ismael SS, Raibaut $\mathrm{P}$, Amarenco G. Pelvic floor muscle activity during coughing: altered pattern in women with stress urinary incontinence. Urology. 2007; 70 (3).

33. Grape HH, Dedering A, Jonasson AF. Retest Reliability of Surface Electromyography on the Pelvic Floor Muscles. Neurourol Urodyn. 2009; 28:395-9.

34. Laycock J. Clinical evaluation of pelvic floor. In: Schussler B, Laycock J, Norton P, Stanton S, editors. Pelvic Floor Re-education. Principles and practice. New York: Springer; 1994.

35. Rett MT, Simões JA, Herrmann V, Marques A de A, Morais SS. Existe diferença na contratilidade da musculatura do AP feminino em diversas posições? Rev Bras Ginecol Obstet. 2005; 27(1): 20-3.
36. Korelo RIG, Kosiba CR, Grecco L, Mato RA. Influência do fortalecimento abdominal na função perineal, associado ou não à orientação de contração do assoalho pélvico, em nulíparas. Fisioter. Mov. 2011; 24(1):75-85.

37. Arab AM, Chehrehrazi M. The Response of the Abdominal Muscles to Pelvic Floor Muscle Contraction in Women With and Without Stress Urinary Incontinence Using Ultrasound Imaging. Neurourol Urodyn. 2011; 30:117-20.

Received: $12 / 02 / 2013$

Recebido: 02/12/2013

Approved: 08/17/2015

Aprovado: 17/08/2015 